Lo Bianco, J. and Slaughter, Y. (2016). The Australia Asia Project. In G. Leitner, A. Hashim and H.-G. Wolf (eds) Communicating with Asia: The Future of English as a Global Language (pp. 296-612). Cambridge University Press. http://www.cambridge.org/gg/academic/subjects/languages-linguistics/ asian-language-and-linguistics/communicating-asia-future-english-global-language?

format=HB\&isbn $=9781107062610$

(C) Cambridge University Press 2016. This publication is in copyright. Subject to statutory exception and to the provisions of relevant collective licensing agreements, no reproduction of any part may take place without the written permission of Cambridge University Press.

\title{
19 The Australian Asia project
}

\section{Joseph Lo Bianco and Yvette Slaughter}

\begin{abstract}
The Australian project of accommodation to the Asia-Pacific region as the dynamic centre of the world's economy can now be dated in decades. Successive Federal and State governments have focused on shifting the national consciousness from its predominant, inherited Western cultural dispositions, towards Asia. Driven by the overriding concerns of trade and economic relations, more than $\$ 400$ million of additional funding has been invested in the prioritization of Asia studies and Asian languages, with considerable additional resources for research, cultural studies, exchanges, etc. Policies and funding have endeavoured to dramatically increase Australia's 'Asia literacy' to aid economic engagement with what has come increasingly to be called 'the region' or 'our region'. All major political configurations adhere to the broad outlines of such engagement, lending the entire endeavour a sense of inevitability; so much so that there is little problematizing of the educational consequences of the shift of economic power from the 'West' to the 'East'. However, despite ambitious plans and substantial funding, Asian language policies have consistently fallen short of targets. This chapter discusses some intricacies involved in formulating an Asia-prioritizing agenda, referring to the wider communication ecology. Language policies must acknowledge the pluralization of modern forms of communication as well as the emergence of multiple cultural and linguistic identities in the transnational reality of contemporary society. The Australian experience highlights the importance of crafting Asia-focused policies within a wider framework of comprehensive language planning (Lo Bianco 2010), that values existing cultural and linguistic diversities, as well as envisioned ones, along with a pragmatic sense of the limits to what can be asked of school knowledge in relation to trade and diplomatic petitions.
\end{abstract}

\subsection{Introduction}

Australian public policy on 'communicating with Asia' can be readily distinguished from counterparts in other parts of the world by several important characteristics. First, what we are calling the 'Australian Asia project' is 
a shared commitment across the national political spectrum, including the most important institutions and large segments of the general population, well beyond the professional concerns of educators or the advocacy of commercial interests. Second, though conceptually arranged under a series of different rubrics at different times, such as 'engagement', Colombo Plan, New Colombo Plan, Asia literacy, Asia capability, Asia competence, or 'regional integration', the idea that a policy is needed to foster 'communicating with Asia' has been a stable presence in government activity, best thought of as a series of programmes in pursuit of a widely endorsed national meta-policy. The overarching aim involves harnessing mainstream educational endeavours to improve communication with Asian societies in response to a shared political interpretation of the national interest. The Asia project has been a stable component of educational investments for the past thirty years, ranging from school to higher and technical education, addressed to general curriculum reform as well as specific language and culture studies, and invariably involving student and staff exchanges. Asia has loomed in Australia's political consciousness over a much longer period, however, defining much of its military, population and education legislation since political Federation in 1901.

\subsection{Reading Asia: the project of Asia literacy}

Australia's relationship with Asia is a multifaceted one, historically complex, and influenced by political allegiances and ideologies, military engagement and rapprochement during the modern era. Unlike European nations, whose relations with Asia involve a degree of optionality, geographic proximity to the Asian land mass has made Australian engagement with Asian states inevitable.

In the nineteenth and early twentieth centuries, the very word 'Asia' functioned to catalyse national anxieties, for the most part differentiated by particular social categories, so that for workers and unions, Asia invoked fears of cheap labour threatening the wages and conditions that their militancy and solidarity had gained. For imperially loyal British-Australians, Asia was already encountered through participation in imperial administration, from India to Malaya, and the Pacific, with connections of family, shared stories and identification with the apparatus and justification of imperial governance. Nationalists, attached to the idea of securing permanence for the British Empire, often invoked Asia as a caution against the social damage which would result from admitting Asian cultures into an Australia perceived to be a distant and vulnerable outpost of Western and specifically British civilization (Lake and Reynolds 2008; Akami and Milner 2013). Even independence-minded nationalists, concerned to forge an autonomous Australian identity with its fusion of Irish and wider European populations, had national security concerns resulting from the large and expanding populations to the north. 
Other than for a few pioneers, such as academics invested in the study of Asian societies, cultures and histories, and some farsighted individuals, pejorative connotations attaching to the term 'Asia' persisted until the last two decades of the twentieth century (Beeson and Jayasuriya 2009). During the transforming ethos that swept Australian education policy in the 1980s, 1990s, and more recently, a radical change has been effected, so that the connotations of Asia are mostly positive, invoking potentially productive relations between interacting societies, representing markets for the destination of Australian raw materials, primary produce, manufactured products and services, including the export of English-medium education.

A key and often neglected dimension of this change has been the greater involvement of the Federal, rather than State, governments, who are constitutionally responsible for education, but more locally focused. Ultimately and decisively, 'Asia' has come to suggest meanings associated with the Federal aspect of governance. Key ones are the population-transforming idea of immigrants as 'new' Australians, of tens of thousands of fee-paying international students sustaining higher education, of accessible attractive holiday destinations, and of direct relations as 'friends and neighbours' (Milner 1999).

This project was incubated through a strategic alliance of knowledge and power, that is, academics and other intellectuals linked to politicians and policy makers. Coinciding with the 'triumph of neoliberalism and the waning of ideological politics of the 1960s' (Beeson and Jayasuriya 2009: 373), these groups interacted to engineer Australia's particular brand of Asia engagement, fuelled by researchers based in universities or think-tanks engaging in policy-influencing work. In their examination of these interactions Beeson and Jayasuriya (2009: 374) describe Asian engagement as both a 'mirror' of 'anxieties and vulnerabilities' and a reflection of debates about the national and political identity of a 'settler society that is both 'in and out' of its immediate region'. They point out that Australia is a multicultural nation solidly ensconced within the Anglosphere, sharing loyalties and identities with the United Kingdom and the United States, but located in Asian geopolitical space. The wider policy culture is one in which key academic figures often move between political, policy-making and academic environments, and this cross-fertilized and sustained the Asia competence national agenda, one intended for the entire population, rather than for a narrow band of specialists.

The idea that Asia competence should be a mass phenomenon is reflected in the national curriculum, Australia's first common curriculum, especially in the provision of what are called 'cross-curriculum themes'. In addition to subjects, generic and specific skills and assessment, the national curriculum contains three 'cross-curriculum priorities': Aboriginal and Torres Strait Islander Histories and Cultures, Asia and Australia's Engagement with Asia and Sustainability (ACARA 2013). These priorities are intended to be incorporated 
across all areas of the study curriculum. The Asia priority 'provides the opportunity for students to celebrate the social, cultural, political and economic links that connect Australia with Asia' (ACARA 2013).

This marks a clear transition from past representations of Australia-Asia relations characterized by maintaining distance and feeling vulnerability, buttressed by broad incomprehension and repudiation. The rhetorical character of the Australian Asia project was expressed first by the work of the Asian Studies Council, a government advisory body created in 1986 to bring about more systematic teaching of Asian perspectives. In its 1988 report it declared: 'the proper study of Asia and its languages is about national survival in an intensely competitive world' (ASC 1988: 2). This instrumentalist remit for study of Asia invokes dramatic consequences of failure (presumably 'national collapse'). This way to mark Asian engagement has become a staple even among sober curriculum writers, for example, the Winter 2009 issue of Education Quarterly Australia issued by Education Services Australia, a company owned by the various ministers of education of states, territories and the federal government, which was titled: Asia literacy - our future.

Between 1969 and 1994, more than forty governmental policies, investigation reports and advisory committees have documented the stocks of knowledge and skill Australia would require in its pursuit of Asian integration, invariably finding a major deficit, and calling for urgent action to increase the number of students enrolled in Asian Studies and learning Asian languages (Henderson 2007). Despite ebbs and flows, considerable progress has been achieved, though far below the targets set by such reports.

Since the mid-1990s, efforts to promote Asia competence have been referred to as 'Asia literacy', riding on the discourse of wider debates concerned with improving general literacy rates, also in the interests of enhanced international economic competitiveness. Asia literacy has two broad components: languages and 'Studies' of Asia. The first designation of an Asian language priority appeared in the 1987 National Policy on Languages (Lo Bianco 1987), in which four Asian languages were included in the nine 'priority languages of wider teaching', specifically, Arabic, Chinese, Japanese and Indonesian. Thereafter, from a 1994 report (COAG 1994), all other languages were removed from consideration and Chinese, Japanese, Indonesian and Korean were deemed the sole priorities, based on advice from the Department of Foreign Affairs and Trade. These four remained the privileged focus for funding, with a federal investment of over \$400 million between 1994 and 2008, an enormous investment in Australian budgetary terms, although Hindi replaced Korean in 2013.

The second component, 'Studies of Asia', involves infusing Asian perspectives into the teaching of mainstream subjects such as history and geography; though in some cases Asian Studies refers to specific curriculum content 
taught directly. A key conceptual component of Asian Studies has been intercultural understanding - not just learning about cultures, which is not necessarily a transformative undertaking in and of itself, but exploring viewpoints, worldviews and culturally based perspectives (Hassim 2013). These developments have not been limited to Asian Studies, since intercultural understanding plays a critical role in the development of language teaching methodology more broadly (e.g., Lo Bianco, Liddicoat and Crozet 1999; Liddicoat and Scarino 2013).

\subsection{National visioning}

Language education policy has often functioned as a barometer of sociopolitical and economic directions and allegiances. During a phase of responsiveness to domestic cultural diversity, from the early 1970s to the late 1980s (Jakubowicz and Ho 2013), the political landscape was defined by the adoption of multiculturalism in public policy and a strong preference for community-heritage languages in schooling and multicultural approaches to curriculum design. During the 1980s, a related but separate movement led to the adoption of a National Policy on Languages (Lo Bianco 1987) which encompassed the linguistic, cultural and educational needs of Australia's diversifying population, and linked both to Asia and a wider internationalism.

From the early 1990s, however, under the influence of neoliberal and trade-focused perspectives in education, the Asian focus prevailed in resource allocations and syllabus/curriculum design. This commenced with the prime ministership of Paul Keating (1991-1996), culminating in the National Asian Languages and Studies in Australian Schools (NALSAS) Strategy (COAG 1994; also Lo Bianco and Slaughter 2009).

The chief architect of NALSAS was Kevin Rudd (former Prime Minister), who went on to become the politician most closely associated with Asia, Asian languages, and a post-European strategy for international engagement (Lo Bianco and Aliani 2013), bolstering the case with his authority as a prominent speaker of Mandarin and an experienced diplomat. The defining element of this undertaking, echoed in all later reports and policies, was the privileging of economic processes over cultural, sociocultural and political dimensions of engagement (Salter 2013). Rudd chose to push the NALSAS programme through the Council of Australian Governments (COAG), the peak intergovernmental body between state/territory and federal leaders, established to facilitate cooperation on issues of national economic significance. It was an entirely unusual forum for an educational policy, but accorded with Rudd's ideological predilections. More tellingly, Rudd had wanted to avoid any explicit references to multiculturalism (Mackenzie 2004). 
Rudd put his stamp on a version of Asian engagement that wanted to render the choice natural and inevitable in light of the deep shift in economic wealth and power from Western (both European and North American) sources to the broader Asia-Pacific; as leader of the Australian Labor Party and eventually Prime Minister, he was uniquely positioned to put his vision into effect. A high profile symbolic moment occurred immediately prior to his winning the prime ministership, when he welcomed the President of the People's Republic of China, Mr Hu Jintao, to a meeting of the Asia Pacific Economic Forum (APEC) in Sydney, in Chinese. His public use of Chinese made national headlines, and was met with both admiration and derision according to the political allegiances of various observers, but the gesture appeared to signal a shift to a concentrated China-centred version of Australia's Asian engagement project (Lo Bianco 2014a). After his election as Prime Minister in 2007, Rudd had a formal mandate to pursue his Asia vision and at a much publicized address at Peking University delivered in Chinese, the Australian media declared him the first political leader of a Western nation to address a public audience in China in Mandarin.

A highly emblematic instance of Rudd's promotion of an Asia-focused Australia was propagated through the 'Australia 2020 Summit', held in April 2008. Under his direct and personal guidance the Summit functioned as a kind of public, continually broadcast and social-media buttressed display of national reconstruction, aiming to chart a new national identity along with a specific political agenda (Lo Bianco and Aliani 2013). Two significant themes arising from the summit were 'to reinvigorate and deepen our engagement with Asia and the Pacific', and 'to ensure that the major languages and cultures of our region are no longer foreign to Australians but are familiar and mainstreamed into Australian society' (Australia 2008b: 35).

A series of 'ambition' comments submitted by individuals and reported in the final 2020 summit document provide interesting insights into the desired change in Australian mentality towards its place in the Asia-Pacific region. The following instance captures the transformative tone and ethos of the summit and Rudd's prime ministership:

By 2020, Australia should be a republic with a female Prime Minister of non-Anglo extraction, a bridge between East Asia and the declining West and a country trusted and accepted as part of Asia. There should be seamless interaction between Australia and the Asian region, its cultures and languages. (Australia 2008a: 399)

Funding for the NALSAS programme had ceased under the previous government, and so Rudd renewed prioritization of Asian language study with a new programme, the National Asian Languages and Studies in Schools Program (NALSSP 2008-12). 


\subsection{Australia in the Asian century}

The 2020 summit vision would mostly remain an unfulfilled ambition, since the vast bulk of its priorities were never implemented and Kevin Rudd was himself replaced as prime minister in an internal Labor Party spill of positions on 24 June 2010. Julia Gillard became the nation's twenty-seventh occupant of the office of head of government, fulfilling at least one small part of the desideratum cited above.

Despite lacking Rudd's long interest in Asia, Gillard soon continued the process of national political and cultural reorientation, commissioning the Australia in the Asian Century White Paper (Taskforce 2012). In the remit for this investigation, Gillard underscored both urgency and spread in its aims:

There is the intellectual task of the White Paper itself: fully to comprehend the implications of the Asian century, fully to describe its opportunities and risks. There is the public task of the process of its development and discussion: to ensure these implications are understood in every part of our nation. (Gillard 2011, n.p.)

Released in October 2012, the White Paper reiterates longstanding economic and strategic motivations for regional engagement. It reads essentially as a document of trade, diplomacy and geopolitical strategy, with schools and languages featuring as service agents of an overarching body of evidence about trade-based national interrelationships (Lo Bianco 2013). What is new is the nomenclature of the Asian project, with the rubric 'Asia capability' substituting the longstanding 'Asia literacy', in the search 'to build 'Asia-relevant' capabilities' from early childhood through to tertiary education, as well as ensuring that business, the public sector and national institutions have the 'right mix of capabilities to seize the opportunities and make the most of Asia's rise' (Taskforce 2012: 161).

However, although Gillard (2011) recognized the emergence of Japan, South Korea, Singapore, Hong Kong, Taiwan, Malaysia, Thailand, Indonesia, Vietnam, China and India in her telling of the rise of Asia, policy recommendations were reduced to the study of four Asian languages - Chinese, Japanese, Indonesian and Hindi.

Initially, the Asian Century White Paper attracted overwhelmingly supportive coverage in the media, but over time a more critical edge emerged as examination showed that the strategy lacked reliable or new funding. What also became clear in the ensuing public debate was that the long experience of Asia-targeted policies has produced a political rhetoric focused on 'inevitablism', essentially that Asia's rise necessarily involves decline of the West and a vast transfer of economic might from the 'West' to the 'East'. This is an essentially uncontested political narrative in contemporary Australia in which the few dissenting voices are limited to calls for more explicit indications of 
how new programmes are to be funded rather than contesting the substance of the policies.

However, accompanying this sense of unstoppable momentum and the need for adaptation is an equally solid sense that Australia's traditional military and political alliances with the United States would remain. The latter was most sharply demonstrated through Gillard's address to a Joint Sitting of the US Congress in March 2011 (Malcolm 2011) and in her speech to the Asia Link and Asia Society later in the same year.

In her address on the 'Asia Century', Gillard interspersed her advancement of the Asia imperative with a clear indication of the foundations which allow for Australia's confident step into the 'East'.

But for Australia, the economic opportunities are how the Asia century begins...[later qualified to say]: It means maintaining strong bilateral relations with our key regional partners. Strengthening new relationships while nurturing existing ones. It means a strong Australia-United States Alliance. A continuing, strong stabilising role for the United States in our region, the vital role it has played now for sixty years...Effective regional institutions, respect for all countries of the region, large and small. Space for a rising China. A robust alliance between Australia and the United States. (Gillard 2011).

It is clear that the Asia Century that Australian conceptions have in mind is one with a central, enduring alliance with a security-providing and Asia-engaged United States.

\subsection{Where do allegiances lie?}

Despite the profusion of reports on the need for 'Asia' competence, and targeted funding programmes for the four prioritized Asian languages, education systems have repeatedly failed to meet the targets set for numbers to be enrolled in these languages, and for the most part language programmes are of insufficient duration and depth to produce the ambitious and, occasionally, naïve targets. Most egregious among these was the 2007 aim that by 2020 'at least 12 per cent of students would complete Year 12 with ... fluency in one of the target Asian languages (Mandarin, Indonesian, Japanese and Korean) sufficient for engaging in trade and commerce in Asia and/or university study' (DEEWR/AEF, 2011: 2).

Given that students spend approximately 600-700 hours studying a language at the secondary level, the target of 'fluency' illustrates a clear lack of understanding on the part of policy-makers of the time/content requirements for effective language proficiency gains. The failure to reach targets has resulted in an ongoing, circular debate around the 'crisis' of Asian language study, declining enrolments (Sturak and Naughten 2010), plummeting student interest and low proficiency attainment (Scarino and Elder 2012). 


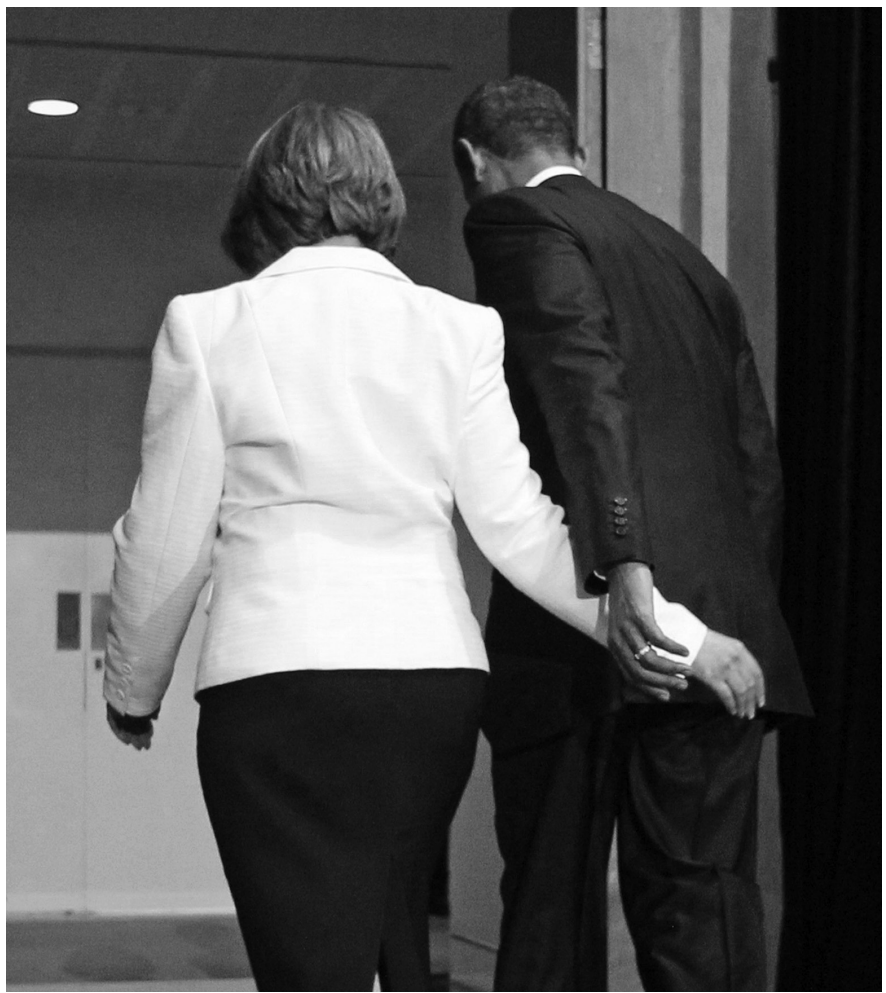

Figure 19.1. President Obama and Prime Minister Gillard entering the Australian Parliament during Mr Obama's November 2011 visit to Canberra. (AP Photo/Charles Dharapak)

The uptake of Asian language study could indeed be construed as a failure, if measured by the overreaching targets of Asia-specific language policy documents. However, at the federal level, contradictory policies and documents have coexisted in recent years. Along with the Asian language focused policies, there has also been a range of general language support statements, such as the National Statement and Plan for Languages (which includes many Asian languages, other than the prioritized four), and the National Indigenous Languages Policy, which have supported the breadth of languages studied in Australia. In addition, the aims and character of the Australian Curriculum also stand in stark contrast to the Asia Century White Paper. The new national curriculum is 'replete with ideas about cultural reciprocity as a critical feature of language learning, and treats the ineradicable multilingualism of Australian life as a necessary component of language planning' (Lo Bianco 2013: 75). 
Table 19.1. Student enrolments by language, Australia, 2006 (Lo Bianco and Slaughter 2009)

\begin{tabular}{lrc}
\hline \hline Language & No. of students & Per cent \\
\hline Japanese & 332,943 & 23.8 \\
Italian & 322,023 & 23.0 \\
Indonesian & 209,939 & 15.0 \\
French & 207,235 & 14.8 \\
German & 126,920 & 9.1 \\
Chinese (Mandarin) & 81,358 & 5.8 \\
Arabic & 25,449 & 1.8 \\
Spanish & 20,518 & 1.5 \\
Greek & 18,584 & 1.3 \\
Vietnamese & 11,014 & 0.8 \\
Other & 45,567 & 3.3 \\
Total & $1,401,550$ & 100 \\
\hline \hline
\end{tabular}

All these policies are evidence of the competing interests that preclude tightly coordinated language planning, with some policy documents promoting objectives which work against the aims of other policy documents.

Given this contradiction of directives, we must ask what is actually occurring in language education in schools. If we measure the success of language planning by a broad rationale, which supports a range of cultural, intellectual and personal motivations for languages education, it would be hard to defend the claim that there is a generalized 'crisis'.

Student enrolments in languages are typically divided between the two major groups of Asian and European languages. Just over 90 per cent of students study one of six languages, around 45 per cent of enrolments are in Indonesian, Japanese and Chinese, and 45 per cent in Italian, French and German (Table 19.1). This pattern is also reflected at the primary school level, although at the secondary level, there is still a slight preference for the top three European languages (40.9 per cent) over the top three Asian languages (35.3 per cent) (Table 19.2).

We can conclude that parents, students and schools only partly share the goals espoused by Asia-prioritizing policies, and that there are multiple reasons and purposes underlying the choice of language. It also might be concluded that language policies that encompass the widest range of rationales for languages study are more effective than highly selective ones with more narrow constructions of the national interest.

\subsection{Funding effects}

While Asia literacy has maintained a high profile in a recently volatile political scene, funding directed to schools for the priority programmes has been 
Table 19.2. Primary and secondary school enrolments, Australia, 2006 (Lo Bianco and Slaughter 2009)

\begin{tabular}{|c|c|c|c|c|c|}
\hline \multicolumn{3}{|l|}{ Primary level } & \multicolumn{3}{|l|}{ Secondary level } \\
\hline Language & No. of students & Per cent & Language & No. of students & $\begin{array}{l}\text { Per } \\
\text { cent }\end{array}$ \\
\hline 1. Italian & 218,301 & 27.8 & 1. Japanese & 156,698 & 20.7 \\
\hline 2. Japanese & 176,245 & 22.4 & 2. French & 137,317 & 18.1 \\
\hline 3. Indonesian & 131,700 & 16.7 & 3. Italian & 103,722 & 13.7 \\
\hline 4. French & 69,918 & 8.9 & 4. Indonesian & 78,239 & 10.3 \\
\hline 5. German & 57,604 & 7.3 & 5. German & 69,316 & 9.1 \\
\hline $\begin{array}{l}\text { 6. Chinese } \\
\text { (Mandarin) }\end{array}$ & 48,405 & 6.2 & $\begin{array}{l}\text { 6. Chinese } \\
\text { (Mandarin) }\end{array}$ & 32,953 & 4.3 \\
\hline Other & 84,127 & 10.7 & Other & 37,005 & 23.8 \\
\hline Total & 786,300 & 100 & Total & 615,250 & 100 \\
\hline
\end{tabular}

Table 19.3. Enrolments in Chinese, Indonesian, Japanese and Korean, Australia, 2000-2008 (Asia Education Foundation 2010)

\begin{tabular}{lccl}
\hline \hline Language & 2000 enrolments & 2008 enrolments & Per cent change \\
\hline Chinese & 78,765 & 92,931 & +18.0 \\
Indonesian & 265,356 & 191,316 & -27.9 \\
Japanese & 419,488 & 351,579 & -16.2 \\
Korean & 3,672 & 3,190 & -13.1 \\
\hline \hline
\end{tabular}

intermittent, resulting, in part, in differential uptake and continuation of Asian language study. Recent figures in Table 19.3 illustrate the varying fates of languages and give an indication of why some commentators claim that language study is beset by crisis.

These figures show that enrolments in Chinese have increased, while enrolments in Indonesian notably declined between 2000 and 2008. It was within this period that funding for the NALSAS programme ceased in 2002, followed by a funding void, then the introduction of the reduced NALSSP programme in 2008. From a much higher base, Japanese, and a much lower base, Korean, both declined.

\subsection{Whose Australia?}

While a clear national focus has been maintained since the mid-1980s, public authorities and government have relied on idealized interpretations of Australian people and of communication and engagement across geographical 
and cultural boundaries. They have continually failed to understand and reflect the linguistic and cultural diversity which constitutes modern-day Australia. They have relied on an antiquated view of us and them, divided by distinct boundaries and languages, and failed to recognize Australia's transformation into a multicultural and multilingual country.

Australia's migration history and priorities have changed significantly since the end of the Second World War. While initial waves of mass migrants were faced with the expectation that they would disassociate themselves from their languages and cultures of origin, significant changes in attitudes and maturing of the national consciousness have allowed for the development of dual and multiple cultural and linguistic identities. The premigration experiences of migrants differ vastly as well, with new Australians arriving, broadly speaking, as refugees, skilled workers and business people. The different routes through which migrants reach Australia can be linguistically, culturally and geographically complex (Clyne and Kipp 2006).

The migrant presence in Australian life was reframed through the embrace of rhetoric and adoption of policies of multiculturalism in the 1970s. Australia's first language policy, the NPL, partly arose from multicultural general policy, and reflected a range of requirements, including the needs of monolingual speakers of English or languages other than English, of multilinguals, and of emerging multilinguals such as migrant and Indigenous children. The rationale underpinning this and other policy frameworks before the 1990s narrowed its focus onto an exclusively trade/security agenda, including the economic, social, cultural and political requirements of a comprehensive approach to national language and literacy needs. The NPL took a broad view of what the national interest is and how it is determined, hence indigenous and immigrant community languages, world languages and foreign languages were all supported, without engaging in the European/Asian dichotomies that have prevailed since.

Currently, around one in five Australians predominantly speaks a language other than English at home. In Sydney and Melbourne, 33 per cent and 29 per cent respectively, do. In the Northern Territory, outside of its capital Darwin, 42 per cent of people speak a language other than English at home, overwhelmingly indigenous languages of which some 200, both recognized languages and dialect forms, and more than 250 migrant languages and dialects, are spoken across Australia (Australian Bureau of Statistics 2012).

This diversity is reflected in the education system, where 133 languages, including fifty indigenous languages, were taught in some kind of formal education programme in 2006. Forty-seven languages were examined nationally. While 97 per cent of students are learning one of only ten languages, many smaller languages are taught by community organizations often supported by public grants under the premises of older policy frameworks (Lo Bianco and Slaughter 2009). But along with the rearing of 
children multilingually in familial environments, what these figures reveal is the linguistic and cultural 'superdiversity' (Vertovec 2007) of contemporary Australia, and underscore our claim that appropriate language policies for such a pluralistic environment cannot ignore the communication ecology of vibrant multilingualism. The advantages of engaging with this communication ecology are not only linguistic, but include the intercultural capabilities inherent in the dual/multiple identities of many Australians. The differing needs of language learners, their personal, familial and identity-based reasons for engaging in language study, and the existing linguistic and intercultural capabilities they offer the nation are completely missed in the reductive and exclusively economically motivated language policies we have been discussing.

However, past national policies are challenged by a further environmental reality. In addition to neglecting community multilingualism, they also fail to recognize the transforming effects of globalization. Identifying economic entities as being coterminous with national states, immune from the accelerating mobility of people, ideas and cultural formations, fails to recognize that national affiliation is increasingly supplemented, disrupted or even subverted by a profusion of individual, familial and professional linkages (Castells 2009; Castles and Miller 2009).

\subsection{Whose Asia?}

One of the most inflammatory issues troubling the prioritization of Asian languages over many decades has been the question of to whom the study of Asian languages belongs (Clyne 2005). The positioning of the Asian languages prioritized in the education system as languages of 'outside' communication has failed to recognize Australians with an Asian heritage situated within its own society, despite descendants of migrants from Asia being long-established in the country, even occasionally 'racializing' their educational experiences (Tan 2005).

The indelible nature of Asian-Australian identity ensures that it is a marker for generation after generation of Asian-Australians. In her study of Australians of Chinese ancestry, Tan (2005: 66-7) argues that racial appearance and 'looks' play a significant role 'in demarcating the boundaries between those who are unconditionally accepted as 'real' Australians'. This phenomenon unfortunately plays out in language classrooms, where students of an Asian heritage are sometimes presumed to have an unfair advantage or even struggle with reconciling their ethnicity with the limitations of their cultural and linguistic capabilities (Slaughter 2008).

Multiple references can be found in newspaper discourse to Chinese surnames among top scorers for Chinese language examinations, as an apparent 
indictor of the unfair advantage Anglo-Australians have to struggle against (Slaughter 2005). Policy making and journalistic reporting on the study of Chinese is underscored by the troubling qualification that most learners of Chinese are of Chinese background; a reservation that alludes to notions of inequity and unfair advantage based on ethnic background. This position unfairly views the students as the problem, rather than considering the failure of policy and curricula to adequately cater to these students and the skills they possess (Lo Bianco 2013).

Curriculum authorities have also been continually challenged to construct courses which exclude or segregate those with an Asian background, who are perceived as having an 'unfair advantage' (e.g., Hyland 2008; Butt and Marshall 2013). Given that the school system by itself will never be able to produce the numbers, range and experiences in languages that are already inherent in the Australian population, it is a recipe for systemic failure for policy to not encompass and develop the nation's intangible cultural heritage (Lo Bianco and Slaughter 2009; UNESCO 2009).

Research into learning achievements in the four prioritized Asian languages have shown that learner groups are highly mixed, with heritage learners (with varying degrees of exposure to their language) and new learners in the same class (Lo Bianco 2012). However, there is no direct correlation between having a linguistic and/or cultural background and performing well across all components of language study, with speaking, reading, listening and writing skills differing significantly depending on, for example, exposure to language, whether a standard form of the language or a dialect is spoken at home, or whether literacy skills have been developed (Elder 2000).

It is not just heritage speakers of languages who need consideration in the curriculum. Research has also revealed differential outcomes for speakers of languages with similar writing and tonal systems, and whether or not the strengths and weaknesses they bring to the language learning classroom are acknowledged (e.g., Scrimgeour 2012).

Such issues address questions of marginalization and discrimination, and are not just confined to Asian Australian contexts. Non-Anglo but non-Asian Australians have also been relegated to the margins, and Asian community language speakers are 'recruited only when convenient to serve short-term utilitarian interpretations of the national interest' (Lo Bianco 2013: 74). Minority languages across Australia have therefore been treated as possible hindrances to greater economic engagement with Asia, as a possible hindrance to integration or loyalty to Australia, or as an obstacle to the acquisition of English. Arguably, there has been at times a fear that Australia should not make itself dependent on minorities, as exemplified by the reporting that Chinese 'is overwhelmingly a matter of Chinese teaching Chinese to Chinese' (Hyland 2008: 8). 


\subsection{What is missing?}

Another flaw in the Australian promotion of Asian communication has been its silence about English in Asia, sometimes significantly denying its presence, as if to bolster the case for direct study of languages, or expressing concern that to acknowledge English and its deep penetration of global, particularly economic, life, is to suggest colonial inclinations. Additionally, in a country such as Australia, language advocates are required to continually reason against the 'English is enough' mentality (Clyne 2005) and are, arguably, quite keen to avoid deeper discussion of the issue. A rare attempt that moves towards an ecological focus on Asian languages and English in the overall communication planning for Asian Australian connections is Leitner (2007), interestingly generated from a German university. This distance perhaps allows the author the perspective that has eluded Australian writers, unwilling to address English in Asia in relation to advocacy of Asian language teaching, and inattentive to the wider motivations and purposes for learning languages that are current in Australian life.

Undoubtedly, English plays an important role in languages education in all of Asia (Cha and Ham 2008), although it is important to note that the acquisition of English is highly stratified, with proficiency levels attained and the kinds of English learned determined by place of residence and socioeconomic opportunity. Effectively, poorer rural children acquire English less well than urban and privileged children (Kirkpatrick 2010a; Lo Bianco 2011). There is a large body of research, with many studies based in Asia, on the importance of mother-tongue based multilingual education, which often gets drowned out by a false but dominant national language/foreign language dichotomy in education systems (e.g., UNESCO 2005, 2007).

Nevertheless, English continues to play a dominant role across the region. It has become the official language of the Association of Southeast Asian Nations (ASEAN) and of the ASEAN Economic Community (AEC) from its inception in 2015 (Kirkpatrick, 2010a). Reconceptualization of English and the teaching of English is also impacting the role of English in Asia. There is no doubt that the predominant reality of English in Asian education remains focused firmly on its native speaker centres. However, it is tempting to speculate that recent reconceptualizations of English in Asia represent a movement away from English as a foreign language, towards English as a lingua franca (e.g., Mauranen and Ranta 2009). The English as a lingua franca movement essentially advocates that the linguistic and pragmatic norms of English communication should be sensitive to local varieties of the language and its local multilingual contexts of use. Closer identification with English as a regionalized lingua franca would arguably contribute to its growing role across domains. One of the implications in considering English as an Asian language 
is that native speakers of English will need to concede space for a fairer communication order to develop. This will provide legitimacy for various forms of English as a Foreign Language, as well as the political enfranchisement of non-native speakers (Lo Bianco 2014b).

This gap in Australia's Asia communication strategy is made deeply ironic by the vast presence of Asian international fee-paying students in Australian schools and universities, many essentially purchasing English-mediated certificates. Failing to grasp the essentially ecological nature of the language learning choices is a significant limitation in how Asian communication programmes have been devised in recent years in Australia.

\subsection{Concluding comments}

The Australian model of Asian language promotion can be described as consisting of externally established targets, imposed timelines and discretionary funding accompanied by a strong top-down rhetoric of 'national survival'. This panoply of activity is directed at schools, teachers and the wider community aiming to secure growth in enrolments in a preferentially determined small number of languages associated most closely with the trade volumes exchanged between Australia and key Asian markets, with the addition of security considerations in relation to Indonesia. This long-term enterprise has been sometimes based on the misguided subtext that 'Asia literate knowledge is all that is needed to invert reliance on Asia and assert Australia's economic dominance' (Salter 2013: 9).

But the privileging of the economic domain carries risks. These include failing to engage directly with student and community interests and excessive narrowing of the purposes and reasons for language study. This can lead to policy initiatives ignoring and potentially alienating large sectors of the community who are excluded from the attentions of such policy because they do not speak or identify with favoured languages. Relying on state to state, or economy to economy, understandings of contemporary life is especially problematical because social media, population movement, study and the transnational realities of twenty-first century living global communication are readily available to most people unmediated by education or government.

Still, the geographical proximity between Australia and Asia provides many of the impetuses for the Australia-Asia communication strategy, including Australia's economic codependency with many Asian nations, as well as significant pan-Asian migration to Australia. In multicultural and multilingual environments such as those experienced across Europe, more geographically distant to Asia in comparison to Australia, the imperative to engage with Asia seems quite dissimilar, but in fact shadows Australia's in many ways. While Asian migration to Europe has been proportionately less, the local, regional 
and European communication ecology must continue to be responsive to the dynamic and changing face of European populations, regardless of the origins of migration. Instances of hostility and xenophobia experienced across the European continent attest to the critical role of intercultural engagement and linguistic accommodation. As Asian migration increases, language and cultural policies must be responsive to the dynamic, changing landscape, in order to support convergence rather than divergence among the many populations of Europe. European education systems must continue to take into account the differing motivations and needs of language learners, including their local, regional and national, as well as familial identity-based reasons for language study.

It could be argued that English fulfils many of the roles in relation to economic, science and technology-based dealings between European and Asian nations and that there is little point in studying Asian languages more broadly. Indeed, English does fill many of these functions. However, it is not as simple as deferring to the notion of English as the international language. Greater consideration needs to be given to the pluricentric and multilingual nature of English as an Asian lingua franca, and to the distinct and varied Asian cultural constructs represented in these evolving forms of English (Sharifian, 2015b). This consideration also extends to the teaching of English in schools and tertiary institutions across Europe. Furthermore, while many dialogues across multilingual and multicultural contexts are mediated through English, it is critical that deeper, longer term economic and cultural exchanges move beyond functional constructions of diplomacy and take into account the growing and negotiated transnational roles of major Asian languages, such as Mandarin and Indonesian/Malay, and important national languages such as Korean, Japanese and Hindi. This is not just a lesson for Australia and Europe, but a broader, global one.

This has been one strength in the continued focus on Asian languages in Australia. While there have been significant faults in Australia's Asia communication strategy, substantial progress, improvement and favourable attitudinal change have occurred, even if well below what it would be reasonable to aspire to with policies more sociolinguistically well informed, less centred on national interest benefit in the economic domain, and more stable and long term. No imaginable position on language and cultural education in Australia could be free of a strong focus on Asia. As the national curriculum is implemented and as review and evaluation of the modest but welcome achievements of the past percolates into public discussion, it is likely that future policy positions will be more nuanced, more inclusive and more successful. 


\section{University Library}

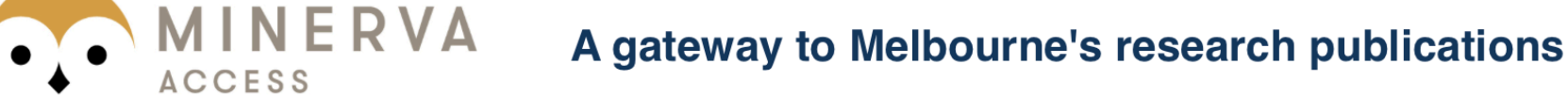

Minerva Access is the Institutional Repository of The University of Melbourne

Author/s:

Lo Bianco, J;Slaughter, Y

Title:

The Australian Asia project

Date:

2016

Citation:

Lo Bianco, J. \& Slaughter, Y. (2016). The Australian Asia project. Leitner, G (Ed.). Hashim, A (Ed.). Wolf, H-G (Ed.). Communicating with Asia: The Future of English as a Global Language, Communicating with Asia: The Future of English as a Global Language, (1), pp.296-312. Cambridge University Press.

Persistent Link:

http://hdl.handle.net/11343/123820 